\title{
Tortura? Como o mecanismo nacional preventivo brasileiro conceitua e analisa práticas de tortura em espaços de privação de liberdade
}

\section{Maria Gorete Marques de Jesus* (1) Thais Lemos Duarte**}

\section{Resumo}

A proposta deste artigo é compreender como o Mecanismo Nacional de Prevenção e Combate à Tortura, órgão do Estado brasileiro em atuação desde 2015, conceitua e analisa as práticas de tortura detectadas em espaços de privação de liberdade visitados no país. Especificamente, pretende-se estudar i) em que circunstâncias este mecanismo identifica determinada violação de direitos como tortura; ii) de que maneira diferencia "tortura" de "maus tratos"; e, por fim, iii) se o órgão estabelece escalas de práticas torturantes, considerando os distintos tipos de estabelecimentos que visitou. A fim de se atingir esses objetivos, foi realizado um estudo dos relatórios produzidos pelo órgão entre 2015 e 2018, o que permitiu concluir que inexiste um padrão de tipificação da prática. A percepção construída pelo órgão sobre tortura é fluida, parecendo estar em disputa e em construção. O artigo propõe que as análises empíricas sobre a atuação do Mecanismo Nacional podem contribuir para a reflexão teórica sobre o fenômeno da tortura, sobretudo no que se refere à questão da prevenção.

Palavras-chave: tortura, tipificação, Mecanismo Nacional de Prevenção e Combate à Tortura.

* Universidade de São Paulo, São Paulo, SP, Brasil.

** Universidade Federal de Minas Gerais, Belo Horizonte, MG, Brasil. 


\section{Torture? How the Brazilian Commission for Prevention of Torture conceptualizes and analyzes torture practices in places of deprivation of liberty}

\section{Abstract}

The purpose of this article is to understand how the Mecanismo Nacional de Prevenção e Combate à Tortura (National Commission for Prevention of Torture), a Brazilian state agency operating since 2015, conceptualizes and analyzes torture practices detected in places of confinement visited in the country. Specifically, it intends to study under what circumstances the National Commission identifies a specific violation of rights as torture; how does it differentiate "torture" from "mistreatment"; and finally, if the agency establishes variations in torture practices, given the different types of establishments visited. To achieve these goals, a study of the reports produced by the agency between 2015 and 2018 was conducted, which allowed us to conclude that there was no standardization of the concept of torture. The organism's perception of torture is fluid, appearing to be in dispute and still being defined. The article proposes that empirical analyzes of the National Commission's performance contribute to the theoretical reflection on the phenomenon of torture, especially regarding the issue of prevention.

Keywords: torture, typification, Mecanismo Nacional de Prevenção e Combate à Tortura.

\section{Foco e objetivos do estudo}

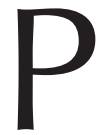

aira no senso comum a percepção de que a tortura remontaria tão somente à Ditadura Civil-Militar, ocorrida entre 1964 e 1985 no Brasil. No período, formalmente enquadrados na Lei de Segurança Nacional, os presos políticos sofreram severas violações físicas e psíquicas por se contraporem a medidas conduzidas por militares e por outros envolvidos no Regime imposto (Arns, 1985). No entanto, a tortura é ato corrente, sendo comum que agentes policiais o cometam durante as abordagens realizadas em suas rotinas de trabalho. De igual maneira, a prática constitui realidade 
viva nas prisões e em outros espaços de privação de liberdade do país ${ }^{1}$, ainda que seja invisível ao debate público (Pastoral Carcerária, 2016).

Movimentos sociais, setores da academia e organizações internacionais de direitos humanos traçam há décadas uma trajetória em favor da construção de políticas voltadas à erradicação da tortura. Em 2013, o Estado brasileiro instituiu o Sistema Nacional de Prevenção e Combate à Tortura, através da lei 12.847, composto pelo Comitê e pelo Mecanismo Nacional de Prevenção e Combate à Tortura (doravante Mecanismo Nacional). Além de prever a criação de ambos os órgãos, a norma incentiva a construção de Mecanismos Estaduais nas distintas unidades da federação.

O Comitê Nacional é um órgão colegiado formado por 23 membros, sendo 11 do Poder Executivo Federal e 12 da sociedade civil (Brasil, 2013a, Art. $7^{\circ}$ ). Também é composto por atores permanentes, como o Conselho Nacional do Ministério Público, o Ministério Público Federal e a Defensoria Pública da União. Conforme previsto em norma, algumas de suas funções centrais são realizar a avaliação periódica da política nacional de prevenção à tortura, acompanhar casos emblemáticos de violações de direitos, propor recomendações e escolher os membros do Mecanismo Nacional (Brasil, 2013a, Art. $6^{\circ}$ ). A primeira composição do Comitê Nacional foi concebida em 2014, estando o órgão vinculado, à época, à Secretaria Nacional de Direitos Humanos.

Já o Mecanismo Nacional é fruto do Protocolo Facultativo à Convenção das Nações Unidas contra Tortura e Outras Penas ou Tratamentos Cruéis, Desumanos e Degradantes (OPCAT), do qual o Brasil é signatário desde 2007 (Brasil, 2007). O órgão, formado por 11 peritos independentes, tem como função central a prevenção e combate à tortura a partir de visitas regulares a espaços de privação de liberdade em todo o país, como prisões, centros socioeducativos, instituições de longa permanência, hospitais

'Entende-se, neste artigo, como "locais de privação de liberdade" os espaços, públicos ou privados, onde indivíduos, seja por mandato, seja por ordem judicial, estejam obrigados a permanecer, sem poder deliberadamente sair. Entre outros exemplos, estariam incluídos nesse conceito os estabelecimentos penais, os centros socioeducativos, os hospitais psiquiátricos, as casas de custódia etc. 
psiquiátricos etc. (Brasil, 2013b, Art. $8^{\circ}$ e $9^{\circ}$ ). Ao término das inspeções, seus membros devem redigir relatórios e propor recomendações a serem remetidas a órgãos estaduais e federais, responsáveis direta ou indiretamente por aspectos concernentes à privação de liberdade.

Para realizar essa tarefa, a Lei 12.847 de 2013 previu uma série de prerrogativas ao Mecanismo Nacional, como o acesso dos peritos a todos os locais de privação de liberdade do país, sejam estes públicos ou privados, sem necessidade de aviso prévio à administração local. Ademais, eles têm permissão para coletar informações e registros relativos às pessoas e aos estabelecimentos visitados, bem como podem entrevistar reservadamente quem puder fornecer informações sobre as condições averiguadas (Brasil, 2013b, Art. 10).

Em exercício desde março de 2015, o Mecanismo Nacional encontrase vinculado administrativamente ao Ministério da Mulher, da Família e dos Direitos Humanos, apesar de legalmente ser um órgão autônomo, constituinte do Estado brasileiro. Seus peritos já visitaram diversos estados do país, produzindo relatórios e emitindo centenas de recomendações a diferentes setores do poder público (Daufemback et al., 2018). O material gerado pelo órgão permite compreender a realidade de privação de liberdade do país, assim como identificar os atos de tortura e de maus tratos comumente praticados.

Assim, supõe-se que o Mecanismo Nacional trabalhe com base em um conceito, ainda que meramente legal, do que seja tortura e maus tratos perpetrados em espaços de privação de liberdade. A proposta deste artigo é compreender como o órgão aborda a questão, por meio da análise dos seus relatórios produzidos entre 2015 e 2018. Especificamente, pretendese analisar i) em que circunstâncias o Mecanismo Nacional identifica determinada violação de direitos como tortura; ii) de que maneira diferencia "tortura" de "maus tratos"; e iii) se o órgão estabelece escalas de práticas torturantes, considerando os distintos locais de privação de liberdade que visitou. 


\section{Dados em análise}

Boa parte dos relatórios e recomendações do Mecanismo Nacional encontra-se disponível na página da internet do Ministério da Mulher, da Família e dos Direitos Humanos². Entre 2015 e 2018, foram publicados quatro tipos de documentos: (i) as "notas técnicas", que sistematizam os posicionamentos do órgão a respeito de determinados aspectos objetivos da privação de liberdade, como, por exemplo, estrutura física dos estabelecimentos penais; (ii) os chamados "relatórios anuais", cujos conteúdos resumem as atividades desenvolvidas durante o período de um ano de atuação do Mecanismo Nacional; (iii) "relatórios temáticos", os quais buscam analisar particularidades da privação de liberdade; por fim, (iv) os "relatórios de visitas", que detalham o encontrado pelos peritos em suas inspeções a unidades de privação de liberdade. Abaixo, estão elencados todos os documentos produzidos pelo órgão entre 2015 e 2018.

No recorte em análise, foram publicizados 41 relatórios com naturezas e configurações diversas. Em todos esses textos foram sistematizadas as atribuições e a metodologia de trabalho do órgão, bem como fatos, narrativas, documentos e quaisquer outros elementos que expusessem as condições de privação de liberdade em um estabelecimento visitado. A maioria exibiu fotos tiradas pelos peritos durante as inspeções.

Tendo em vista esse material, as discussões a seguir encontram-se divididas conforme três debates centrais, baseados nos objetivos específicos deste artigo. Para desenvolvê-los, trechos dos relatórios do Mecanismo Nacional foram categorizados a partir dos seguintes elementos: a) aspectos gerais sobre a conceituação de tortura proposta pelo órgão, como normativas utilizadas e o modo pelo qual essas leis costumam ser interpretadas; b) as diferenciações entre as práticas compreendidas como "tortura" e as identificadas como "maus tratos"; e c) as especificidades sobre as violações cometidas nos distintos espaços de privação de liberdade visitados pelo ente.

${ }^{2}$ Os Relatórios do Mecanismo Nacional de Prevenção e Combate à Tortura estão disponíveis no site https://mnpctbrasil.wordpress.com/relatorios/. 
Em outras palavras, esses três pontos direcionaram a leitura dos documentos utilizados na pesquisa e, portanto, fundamentaram as análises propostas.

Quadro 1 - Documentos produzidos pelo Mecanismo Nacional entre 2015 e 2018

\begin{tabular}{|l|l|}
\hline \multirow{2}{*}{ Relatórios anuais } & $\begin{array}{l}2015-2016 \\
2016-2017 \\
2017-2018\end{array}$ \\
\hline \multirow{2}{*}{ Notas técnicas } & $\begin{array}{l}\text { "Nota Técnica no 01.2016 MNPCT - Posicionamento sobre a PEC da redução } \\
\text { da maioridade penal" - 2016. } \\
\text { "Nota Técnica no 02.2017 MNPCT - Posicionamento sobre o Substitutivo } \\
\text { ao PL 7.197/2002 - Aumento do Tempo de Medida de Internação e outras } \\
\text { mudanças no sistema socioeducativo" - 2017. } \\
\text { "Nota Técnica Conjunta MNPCT, LabGEPEN e NuPES - 2018: Análise sobre } \\
\text { Os impactos da alteração da Resolução 09, de 18 de novembro de 2011, do } \\
\text { CNPCP que define as Diretrizes para Arquitetura Penal no Brasil" - 2018. }\end{array}$ \\
\hline $\begin{array}{l}\text { Relatórios } \\
\text { temáticos }\end{array}$ & $\begin{array}{l}\text { Massacres prisionais dos estados do Amazonas, do Rio Grande do Norte e de } \\
\text { Roraima. } \\
\text { FUNPEN e prevenção à tortura: as ameaças e potenciais de um fundo } \\
\text { bilionário para a prevenção à tortura no Brasil. } \\
\text { Relatório de inspeção nacional em comunidades terapêuticas. }\end{array}$ \\
\hline $\begin{array}{l}\text { Relatórios de } \\
\text { visitas a unidades } \\
\text { com restrição de } \\
\text { liberdade }\end{array}$ & $\begin{array}{l}\text { Região Norte: Amazonas, Pará, Rondônia, Roraima e Tocantins. } \\
\text { Região Nordeste: Ceará, Maranhão, Paraíba Pernambuco, Piauí e Rio Grande } \\
\text { Rogião Centro-Oeste: Distrito federal, Goiás, Mato Grosso e Mato Grosso do } \\
\text { Sul. } \\
\text { Região Sudeste: Espírito Santo e São Paulo. } \\
\text { Região Sul: Rio Grande do Sul e Santa Catarina. }\end{array}$ \\
\hline
\end{tabular}

Fonte: Mecanismo Nacional de Prevenção e Combate à Tortura.

Antes de apontar as observações a serem extraídas dos relatórios do Mecanismo Nacional, realiza-se uma descrição do histórico do enfrentamento das práticas de tortura no Brasil e uma discussão conceitual, teórica e analítica sobre a questão.

\section{Concepções sobre privação de liberdade e tortura}

Muitos documentos e manuais de direitos humanos apontam para a vulnerabilidade de pessoas privadas de liberdade (APT, 2014). Entende-se que o indivíduo cerceado de seu direito de ir e vir, seja em consequência de uma medida judicial, seja em razão de um impedimento físico, apresenta 
menores chances de se proteger e de expor uma violação a que esteja submetido. Esse tipo de percepção abre margem a uma reflexão sobre as motivações sociais de se privar certa pessoa ou grupo de liberdade, bem como o porquê de a tortura ser prática comumente executada em estabelecimentos de detenção.

De antemão, é possível dizer que a privação de liberdade assume diferentes funções, de acordo com o contexto em que se insere. Seria equivocado analisar a pena de prisão, por exemplo, de modo puramente abstrato, sendo necessário situá-la conforme seu cenário de aplicação (Bozza, 2013). Portanto, em um Estado Absolutista, imperou o suplício dos condenados, cujo objetivo era a punição em si (Foucault, 2008), não havendo a necessidade de reparação da falta cometida. A pena era a finalidade máxima. Por outro lado, com o advento do capitalismo em sociedades ocidentais, formou-se o Estado burguês, fundamentado no contrato social, permeado por ideias iluministas. Partia-se da hipótese de que os indivíduos celebravam um acordo, no qual delegavam a certos órgãos a garantia da sua convivência. Como a lei penal costumaria restringir o indivíduo em sua liberdade de agir, não seria possível proibir mais do que o necessário para se atingir uma coexistência considerada pacífica (Roxin, 2008). Em outras palavras, uma vez que passa a ser percebida como a intervenção mais grave do Estado na liberdade individual, a pena só poderia ser cominada quando não houvesse outras formas mais brandas para se alcançar determinada situação desejada. A sanção penal deveria ser exceção e não a regra.

Beccaria (1996), importante pensador iluminista, expõe a necessidade de tais princípios ao âmbito jurídico moderno:

(...) somente as leis podem fixar as penas para os delitos; e essa autoridade só pode ser o legislador, que representa a sociedade unida por meio de um contrato social. Nenhum legislador pode, com justiça, infligir penas a outros membros dessa mesma sociedade. Mas, uma pena agravada além do limite fixado nas leis, é a pena justa acrescida de outra pena: não pode, assim, um magistrado, sob qualquer pretexto de zelo, ou do bem público, aumentar a pena estabelecida para um cidadão delinquente (Beccaria, 1996, p. 19). 
Portanto, a privação de liberdade, especificamente a pena de prisão, sobressaiu-se a todos os demais tipos de sanções sociais e apresentou como diferencial o seu ajustamento ao indivíduo infrator (Foucault, 2008). Desenvolveu-se, pois, a noção de periculosidade, cujo efeito era fazer com que o indivíduo fosse analisado pela sociedade ao nível de suas virtualidades e não de seus atos. Privar alguém do seu direito de ir e vir, como um delinquente ou uma pessoa em transtorno psíquico, visaria corrigir não só os comportamentos, mas também as atitudes, disposições, perigos e possíveis aspirações individuais.

Weber (2004) apontou que as sociedades capitalistas não empregariam como operários as pessoas percebidas como "indisciplinadas", bem como não abarcariam as pessoas consideradas "sem escrúpulos" para as funções de "homens de negócios". O indivíduo ideal era aquele com forte domínio de si mesmo e grande sobriedade. De igual maneira, Elias (1993) pontuou a importância do Processo Civilizador para o desenvolvimento das sociedades burguesas, já que compeliu os indivíduos a controlar suas paixões e pulsões internas com vistas a evitar situações imponderadas e desagradáveis, desconexas do ethos preponderante no mundo burguês. A previsibilidade, a regularidade e a racionalização deveriam ser marcas centrais dos indivíduos modernos.

Os estabelecimentos de privação de liberdade poderiam ser interpretados, pois, como um mecanismo de modelagem de indivíduos considerados indesejáveis. Ou seja, teriam a função de transformar seres analisados socialmente como improdutivos e dispersos em agentes úteis. No limite, objetivariam alijar indefinidamente estes indivíduos daqueles considerados "produtivos", aptos a viver em liberdade. Não à toa, Goffman (2007) identificou tais espaços como "instituições totais", onde a identidade do sujeito é sistematicamente mortificada, havendo uma série de rebaixamentos, degradações, humilhações e profanações do eu. O indivíduo passaria por transformações radicais em sua carreira moral, "uma carreira composta pelas progressivas mudanças que ocorrem nas crenças que têm a seu respeito e a respeito dos outros que são significativos para ele" (Goffman, 2007, p. 24). 
No que tange ao cenário brasileiro contemporâneo, não é possível apontar que os estabelecimentos de privação de liberdade, como prisões e centros socioeducativos, sejam instituições totais, nos moldes propostos por Goffman (2007). Godoi (2011) já teria chamado a atenção para as porosidades desses ambientes, os quais costumam ser fortemente permeados pela ação dos chamados vasos comunicantes, como, entre outros, visitantes, assistentes religiosos e funcionários. Esses atores trariam sistematicamente valores do "lado de fora" aos espaços de privação de liberdade, evitando que tais ambientes se distanciassem efetivamente do mundo "em liberdade", como proposto pelo sentido clássico.

Se, no período moderno, a tortura poderia ser compreendida como uma das ferramentas utilizadas no processo de docilização de indivíduos tidos como socialmente indesejados, atualmente, a prática continua a ser instrumento de submissão e subordinação, sobretudo, de pessoas pertencentes a classes menos abastadas economicamente. A diferença reside no fato de que a tortura era antes utilizada em larga escala como forma de violência legítima (Gomes, 2017). Nos dias atuais, tornou-se prática ilegal, mas, ainda assim, regularmente executada contra certos grupos, como será discutido adiante. Em outras palavras, a tortura é violência disseminada, utilizada como método de investigação, punição e castigos, mesmo em países com democracias consideradas consolidadas (Cardia; Astolfi, 2014). A prática, pois, é instrumento de gestão e manutenção da ordem, em um sistema mormente pautado por violações de todas as naturezas.

Surgem, então, órgãos como o Mecanismo Preventivo brasileiro, assim como organizações da sociedade civil que buscam historicamente enfrentar a prática. As ações desses atores são discutidas nas seções a seguir.

\section{Breve histórico do enfrentamento à tortura no Brasil}

A transição democrática de 1980 apresentou uma grande pressão social para que o Estado brasileiro constituísse uma política de enfrentamento à tortura, cuja abrangência se ativesse desde a formulação de legislações 
criminalizando a conduta, até políticas públicas de prevenção e combate. Nessa direção, a Constituição de 1988, em seu artigo 5ㅇIII, fez expressa proibição a esse tipo de ato ao ressaltar que "ninguém será submetido à tortura nem a tratamento desumano ou degradante".

A construção de políticas para erradicação da tortura via legislação, desde então, percorreu duas trajetórias: uma visava a criminalização da tortura, enquanto a outra buscava medidas preventivas (Angotti; Jesus; Jesus, 2018). Nesse sentido, em 1992, o Brasil ratificou a Convenção Contra a Tortura e Outros Tratamentos ou Penas Cruéis, Desumanos ou Degradantes (1984).

Por sua vez, nos primeiros anos de 2000, ocorreu a visita do Relator da ONU contra a tortura, Sir Nigel Rodley, seguida da emissão de um relatório contendo trinta recomendações (Rodley, 2001). Esse documento serviu de pano de fundo à política nacional construída ao longo dos anos seguintes. Seu mote era de que a tortura seria erradicada, caso fossem adotadas estratégias que limitassem a sua perpetração. Em boa medida, essa concepção se conecta à abordagem da Criminologia, cujo objeto central seria a vítima, investigando como estilos de vida e oportunidades geradas por certos indivíduos influenciam a probabilidade de vitimização (Cohen; Kluegel; Land, 1981). Conforme Beato, Peixoto e Andrade (2004), os fatores que mais motivariam o risco de alguém sofrer algo seriam a exposição, a proximidade entre a vítima e o agressor, a capacidade de proteção, os atrativos das vítimas e a natureza dos delitos.

Essa perspectiva se alinha à chamada teoria dos "crimes de oportunidade", em que determinadas condições de risco favorecem o cometimento de um crime. A partir dessa lógica, foram criados diversos instrumentos nacionais voltados à prevenção à tortura, como o Plano Nacional Contra Tortura, Campanha de Combate à Tortura $(\mathrm{MNDH}, 2003)^{3}$,

${ }^{3}$ Foi estabelecido um convênio entre o Ministério da Justiça, a Secretaria de Estado de Direitos Humanos (atual Secretaria Especial de Direitos Humanos) e a Sociedade de Apoio aos Direitos Humanos, órgão representativo do Movimento Nacional de Direitos Humanos $(\mathrm{MNDH})$. 
Protocolo de Ação contra a Tortura (Brasil, 2003), Plano de Ações Integradas para Prevenção e Controle da Tortura no Brasil (PAIPCT) (Brasil, 2005).

Concomitantemente e com o mesmo mote teórico, em 2002, as Nações Unidas discutiam o Protocolo Facultativo à Convenção contra a Tortura e Outros Tratamentos ou Penas Cruéis, Desumanos ou Degradantes (OPCAT). Este documento fomentou a ideia de que os potenciais perpetradores somente praticam atos de violência quando os ganhos superam os custos marginais ${ }^{4}$, como a possibilidade de ser responsabilizado. O monitoramento constante das ações dos agentes do Estado seria uma estratégia dissuasória da tortura, ao mesmo tempo em que publicizaria os possíveis atos violentos e arbitrários.

O Protocolo definiu alguns conceitos-chave, como "monitoramento preventivo" e "locais de privação da liberdade", além de ter criado o Subcomitê de Prevenção à Tortura (SPT). Previu também que seus países signatários deveriam criar o "Mecanismo Nacional de Prevenção à Tortura". Esses órgãos seriam instituídos por lei, compostos por membros da sociedade civil e escolhidos de forma independente, tendo atribuições parecidas com as indicadas anteriormente, relativas ao Mecanismo Nacional brasileiro. As funções de seus integrantes seriam remuneradas, devendo ser exercidas com autonomia funcional e financeira (Angotti; Jesus; Jesus, 2018).

Antes de ratificar o Protocolo, o então presidente da República apresentou um decreto em 2006 para instituir o Comitê Nacional de Prevenção e Combate à Tortura, composto por entidades da sociedade civil e membros do poder público ${ }^{5}$. O órgão teve papel importante na elaboração do texto do Projeto de Lei 2.442/2011, que criava o Mecanismo Nacional de Prevenção à Tortura. O documento original foi substancialmente alterado durante sua tramitação, com mudanças que excluíram disposições que

${ }^{4}$ Como exemplos, a obtenção de confissão, informação ou mesmo ganhos pessoais.

${ }^{5}$ Pastoral Carcerária Nacional, o Centro para a Justiça e o Direito Internacional (CEJIL), Movimento Nacional de Direitos Humanos, Conselho Federal de Psicologia e Ordem dos Advogados do Brasil, Ministério da Justiça, a Secretaria de Direitos Humanos, Ministério das Relações Exteriores, Ministério Público Federal, um representante do Ministério Público estadual e um representante do Judiciário. 
garantiam a independência do Mecanismo, sobretudo, as que exigiam um processo de composição aberto e participativo, com membros da sociedade civil, nomeados a partir de seleção pública (Angotti; Jesus; Jesus, 2018).

Após anos de tramitação, foi aprovada a já citada Lei 12.847/2013. Apesar de representar avanços, a legislação não esgotou todas as questões importantes à execução das atividades do Mecanismo e do Comitê Nacional, deixando parte para ser regulada por Decreto, como o de n 8.154/2013, e por outros atos da administração pública, como os proferidos em Diário Oficial. Os cargos concedidos aos membros do Mecanismo Nacional em seus primeiros anos de atuação, por exemplo, não foram previstos em lei, estando dispostos em normas alteráveis por ato da Presidência da República, sem a obrigatoriedade de passar pelo crivo do Congresso Nacional (Angotti; Jesus; Jesus, 2018).

Em consequência, a depender de circunstâncias políticas, as quais costumam estar muito conectadas à natureza do governo em curso em determinada época, as rotinas do Mecanismo e do Comitê Nacional se sujeitam à discricionariedade dos gestores públicos. Supõe-se, então, que um governo mais adstrito a parâmetros internacionais de direitos humanos tenderia a respeitar a autonomia do Mecanismo Nacional, mas, em situação contrária, traços fundamentais ao seu funcionamento, como os indicados pelo Protocolo, poderiam ser colocados em xeque.

Corroborando essa hipótese, em junho de 2019, o governo Jair Bolsonaro lançou o Decreto $n^{\circ}$ 9.831, cujo efeito foi mudar a estrutura de cargos em comissão do Ministério da Mulher, da Família e dos Direitos Humanos, alterando o Decreto $n^{\circ} 8.154 / 2013$. Tal norma desconsiderou as atividades desenvolvidas pelos peritos do Mecanismo Nacional como assalariada, identificando-as como prestação de serviço público não remunerada (Art. 10, §5ㅇ), que não pode ser exercida por pessoas vinculadas a redes, a entidades da sociedade civil e a instituições de ensino e pesquisa. Todos os peritos em atuação no período de lançamento do decreto foram imediatamente exonerados. 
Diversas organizações da sociedade civil e órgãos públicos vinculados à pauta questionaram a postura governamental. Como exemplo, um documento ventilado pelo Colégio Nacional dos Defensores Públicos Gerais indicou que

[a] precarização do Mecanismo Nacional de Prevenção e Combate à Tortura, por meio do estabelecido no Decreto no 9.831/2019, viola o compromisso brasileiro de efetivação dos direitos humanos e de suas respectivas garantias, atingindo de forma direta o direito absoluto e inderrogável da proibição à tortura (Condege, 2019).

A constituição do Sistema Nacional de Prevenção e Combate à Tortura e, por sua vez, a formação do Mecanismo e do Comitê Nacionais são apenas um capítulo adicional ao histórico do enfrentamento à tortura no Brasil. Muito ainda está em disputa no que tange a essa recente e frágil política nacional.

\section{Debates e conceituações sobre tortura}

Embora praticada desde os tempos mais recuados da história e explicitamente condenada pelo artigo $V$ da Declaração Universal dos Direitos Humanos de 1948, a tortura só veio a ser definida juridicamente em 1984, através da Convenção Contra a Tortura e Outras Penas ou Tratamentos Cruéis, Desumanos e Degradantes (Comparato, 2010). Além de abarcar essa normativa, o Brasil dispõe de outras referências legais sobre o crime, como as relativas à Convenção Interamericana para Prevenir e Punir a Tortura, de 1989, e a Lei Federal 9.455 de 1997. As três normas não são necessariamente díspares, mas apresentam nuances significativas.

Segundo o artigo 1ํ da Convenção da ONU, a tortura é definida como qualquer ato cometido por agentes públicos ou por atores no exercício da função pública pelo qual se inflija intencionalmente a uma pessoa dores ou sofrimentos graves, físicos ou mentais, a fim de: a) obter informação 
ou confissão; b) de castigá-la por um ato que praticou ou que se suspeite que tenha desenvolvido; c) intimidar ou coagir; ou d) por qualquer razão baseada em algum tipo de discriminação.

Por sua vez, o Artigo 2 o da Convenção Interamericana para Prevenir e Punir a Tortura apresenta uma tipificação mais extensiva, admitindo-se que o ato seja desenvolvido com vistas a anular a personalidade da vítima, prática não indicada na previsão das Nações Unidas:

[t]odo ato pelo qual são infligidos intencionalmente a uma pessoa penas ou sofrimentos físicos ou mentais, com fins de investigação criminal, como meio de intimidação, como castigo pessoal, como medida preventiva, como pena ou qualquer outro fim. Entender-se-á também como tortura a aplicação, sobre uma pessoa, de métodos tendentes a anular a personalidade da vítima, ou a diminuir sua capacidade física ou mental, embora não causem dor física ou angústia psíquica (Brasil, 1989, artigo 2º).

Embora tenha anteriormente abarcado essas normas em seu arcabouço legal, a criminalização da tortura no Brasil apenas se efetivou em 1997. A despeito das históricas lutas sociais em torno do tema, a Lei 9.455 foi promulgada a "toque de caixa" (Jesus, 2010), muito em consequência da comoção popular ensejada pela divulgação de imagens de policiais militares torturando moradores da região de Diadema em 1997, em São Paulo6 . Até então, os casos denunciados eram julgados com base na Lei de Abuso de Autoridade (Lei 4.898/65) ou como lesão corporal e maus tratos (Jesus, 2010). A tortura era apenas citada como agravante do Código Penal, por exemplo, como qualificadora de crime de homicídio.

\footnotetext{
${ }^{6}$ Imagens gravadas por um cinegrafista amador mostravam um grupo de policiais militares praticando extorsão, espancamento, tortura e humilhando moradores em uma blitz na Favela Naval, em Diadema, subúrbio de São Paulo. Em consequência, a Assembleia Legislativa de São Paulo anunciou a criação de uma Comissão Parlamentar de Inquérito para apurar o caso e, em 3 de abril, foi aprovado pelo Congresso o projeto de lei que transformava a tortura em crime com pena de até 21 anos de prisão. Informações disponíveis em: http:// memoriaglobo.globo.com/programas/jornalismo/telejornais/jornal-nacional/favela-naval. htm.
} 


\section{A Lei Federal 9.455/1997 tipifica como tortura:}

[c] onstranger alguém com emprego de violência ou grave ameaça, causandoIhe sofrimento psíquico ou mental com a finalidade de obter informação, declaração ou confissão da vítima ou de terceiros; para provocar ação ou omissão de natureza criminosa; em razão de discriminação racial ou religiosa (Brasil, 1997).

A prática é punida com pena de reclusão de dois a oito anos, aumentando-se de um terço até um sexto se cometida a) por agente público; b) contra criança, gestante, portador de deficiência, adolescente ou maior de 60 anos; e c) mediante sequestro. O crime é inafiançável e insuscetível de graça ou anistia.

São realizadas algumas críticas à tipificação nacional por não conseguir absorver uma série de aspectos sociais estruturantes. Nesse sentido, a tortura deve ser analisada como fenômeno altamente complexo, invisível, indizível, insindicável e impunível (Maia, 2006). Invisível, porque ocorre em locais de pouca visibilidade, como distritos policiais, carceragens, penitenciárias, unidades de internação etc. Indizível, pois as vítimas e possíveis testemunhas têm de enfrentar o medo e prováveis represálias para denunciar a tortura. Insindicável, porque existe um fator corporativista entre quem apura e quem é investigado. Impunível, pois poucos casos alcançam o sistema de justiça criminal; quando chegam, não há qualquer certeza sobre a responsabilização dos acusados.

Portanto, o conceito jurídico estaria longe de abranger esse tipo de abordagem sobre a tortura. Em primeiro lugar, a legislação nacional definiu o crime como de tipo comum e não próprio, como abordado pelos tratados internacionais, podendo ser cometido por agente privado. Pesquisas indicam que essa característica da norma impacta o julgamento da tortura (Jesus, 2010), pois os casos ocorridos em âmbito privado estão mais sujeitos à apuração e condenação, em detrimento de fatos cometidos por agentes públicos, como os que ocorrem em prisões (Calderoni; Jesus, 2015; Salla; Jesus; Jesus, 2016). Em consequência, o sistema de justiça criminal invisibiliza 
a tortura, bem como dilui e relativiza a responsabilidade do Estado sobre a questão, projetando com maior força fatos que, embora graves, poderiam receber outro tipo de relevo (Jesus, 2010).

Outra consequência da tipificação nacional decorre da possibilidade de desclassificação do crime de tortura para outros tipos penais, como maus tratos, prática tratada com menor rigor pelo sistema de justiça criminal (Jesus, 2010). O Código Penal, em seu Artigo 136, define que este tipo de crime consiste na exposição a perigo da vida ou da saúde de pessoa sob a autoridade, guarda ou vigilância do agente, para fim de educação, ensino, tratamento ou custódia, quer privando-a de alimentação ou cuidados indispensáveis, quer sujeitando-a a trabalho excessivo ou inadequado, quer abusando de meios de correção ou disciplina. O ato é punível com pena de detenção de dois meses a um ano ou multa. Caso resulte em uma lesão corporal de natureza grave, é penalizado com reclusão de um a quatro anos. Se resultar em morte, reprime-se em privação de liberdade de quatro a 12 anos.

Conforme Franco (1998), tanto em casos de tortura quanto de maus tratos, a objetividade jurídica é a mesma, ou seja, a vida e a saúde humanas. A distinção consiste no tipo de ação de quem comete o delito. Ou seja, nos maus-tratos, o agressor expõe a vítima ao dano, ao passo que, na tortura, o perpetrador provoca o dano à vítima. Em adição, o crime de maus tratos é cometido como abuso do ius corrigendi (direito de correção) para fins de educação, de ensino, de tratamento ou de custódia. O castigo aparece como meio de ensinar uma lição, corrigindo um ato considerado inaceitável. Já no crime de tortura, o agente pratica a conduta como castigo pessoal ou como medida de caráter preventivo (Franco, 1998).

O legislador também optou por não detalhar a prática de tortura, tornando-a um tipo penal aberto, cuja definição depende em boa medida do aplicador da lei (Jesus, 2010). Isto é, inexiste uma descrição completa do que efetivamente seja tortura, fornecendo a possibilidade de o intérprete da norma captar ao seu rigor aspectos do ato praticado, subsumindo-os à sua interpretação do que seja tortura dentro do minimamente traçado em 
lei. A leitura sobre o fato se torna muito mais contextual, ao invés de se embasar em parâmetros objetivos, previamente estabelecidos.

Uma conceituação importante à tipificação da tortura, mas que também se dilui frente à conceituação imposta pela lei nacional, gira em torno da noção de "omissão". Estão previstas duas situações para sua ocorrência. Por um lado, "quem, tendo o dever de evitar a prática da tortura, omite-se" e, por outro, "quem, tendo o dever de apurar a prática da tortura, omite-se" (Maia, 2006, p. 152). O artigo $13 \S 2^{\circ}$ do Código Penal estabelece que a omissão implica na responsabilização de quem teria o dever de evitar um crime, mas não o impediu. E, ainda, quem teria o dever de apurar o delito, porém não o fez. De fato, há pouco insumo sobre o tema. São raras as denúncias por omissão que chegam ao sistema de justiça criminal e, quando o fato ocorre, há uma tendência de prescrição por morosidade ou os acusados são absolvidos por falta de provas. Geralmente, as pessoas passíveis de serem denunciadas por omissão são envolvidas nos processos judiciais como testemunhas, compondo a defesa dos agentes acusados da prática de tortura (Jesus, 2010).

Face a essas diferentes conceituações e às disputas colocadas no cenário jurídico penal brasileiro, as seções a seguir buscam detalhar como o Mecanismo Nacional mobiliza as definições sobre tortura em seus relatórios de visitas a espaços de privação de liberdade.

\section{Narrativas do Mecanismo Nacional}

Nesta seção, inicialmente discute-se como o Mecanismo Nacional identifica em seus documentos determinada violação de direitos como tortura. Em seguida, analisa-se de que maneira são diferenciados "tortura" e "maus tratos". Por fim, propõe-se detectar possíveis variações de práticas de tortura, segundo os distintos estabelecimentos visitados pelo órgão. 


\section{Aspectos gerais}

A primeira observação a se extrair da análise dos relatórios do Mecanismo Nacional se refere ao fato de inexistir um padrão sobre como se mobilizam as distintas tipificações de tortura. Geralmente, em meio a seções descritivas sobre os espaços monitorados, indicou-se superficialmente as definições previstas na Convenção da ONU e na Lei 9.455/1997, sem ter sido proposta, porém, uma interpretação mais refinada sobre as normativas. De maneira semelhante, raros são os textos que mencionam a conceituação alvitrada pela Convenção Interamericana, embora também tenham sido ocultadas as motivações sobre o uso dessa norma em algumas circunstâncias.

Alguns documentos publicados, em 2016, buscaram também conceituar "prevenção", conforme definição prevista em dicionário. Portanto, estipulouse uma descrição puramente literal do termo, sem problematizações adstritas a campos do conhecimento alinhados à esfera de atuação do Mecanismo Nacional, como o jurídico, por exemplo, o qual poderia suscitar debates jurisprudenciais. Entretanto, a definição também pareceu ter uso fluido, surgindo em alguns textos, mas desvanecendo em outros:

[s] egundo o Dicionário Aurélio, prevenir é: dispor de antemão, preparar; precaver; avisar, informar, advertir; tratar de evitar, acautelar-se contra; livrarse de; evitar; impedir; predispor favorável ou desfavoravelmente o ânimo dispor-se; precaver-se, precatar-se. O trabalho do MNPCT é de prevenção à tortura (Brasil, 2016d, p. 4).

Há textos do Mecanismo Nacional que sequer utilizaram o termo "tortura" para se referir às práticas encontradas em estabelecimentos visitados, ainda que estas sejam identificadas pelos peritos como graves. O relatório atinente ao Presídio Militar Romão Gomes, em São Paulo, seria o mais emblemático nesse sentido (Brasil, 2015f). Quando descrita, a violação teria sido identificada como "maus tratos", conforme será analisado na seção adiante.

Se existe algum padrão nos documentos analisados, é possível apontar que todos pareceram se ater mais à identificação de fatores de risco que 
acarretam a tortura, ao invés de levantar casos concretos. Os relatórios se ativeram a aspectos coletivos observados nas unidades de privação de liberdade, não descrevendo situações individuais, nas quais estariam discernidos os possíveis autores de tortura e suas vítimas. Em adição, há de se ressaltar também os muitos trechos dos documentos em que os peritos estabeleceram uma relação direta entre o termo genérico "tortura" e determinadas ações tidas como contrárias a padrões de direitos humanos, sem qualquer tipo de aprofundamento. Um documento referente a um estabelecimento de saúde mental apontou que “(...) esta unidade não só alija os indivíduos do contato com a comunidade, como também impõe condições de privação de liberdade que não respeitam a dignidade humana, tornando-se palco de práticas de tortura (...)" (Brasil, 2015e, p. 13). Não foram fornecidas maiores explicações sobre como o cenário descrito seria propício à perpetração do ato.

Alguns textos do Mecanismo Nacional, porém, permitiram reflexões um pouco mais consistentes, pois foi realizado relativo esforço de subsumir práticas averiguadas ao disposto em lei. Na narrativa a seguir, relacionouse o uso desmedido da força efetuado por policiais em uma unidade socioeducativa ao intenso sofrimento psíquico e físico ao qual os adolescentes se encontravam submetidos:

[e]ssas rebeliões são reprimidas com um uso desmedido da força por parte da Polícia Militar. Relatórios e relatos da sociedade civil apontaram para uma abusiva utilização de armamentos menos letais, como sprays de pimenta, jatos d'água e balas de borracha (Brasil, 2016b, p. 13).

Com o mesmo mote, em seu primeiro relatório anual, o Mecanismo Nacional forneceu um rol de práticas identificadas como rotineiras em detenções em flagrante conduzidas por policiais. Por gerarem intencionalmente forte sofrimento físico, por serem cometidas por agentes do Estado e por serem realizadas com vistas a punir, coagir ou discriminar alguém, o órgão indicou que tais ações poderiam ser enquadradas como tortura: 
(...) foram narradas ao MNPCT as seguintes práticas de tortura cometidas por policiais nos estados: espancamentos; queimaduras; choques elétricos nos genitais; afogamento; sufocamento com saco plástico; perfuração abaixo das unhas; "telefone" (bater nas duas orelhas simultaneamente); remoção de unhas; humilhações verbais; ameaças (Brasil, 2016a, p. 29).

Portanto, ao passo que, em alguns documentos, a prática ganhou aspecto vago ou sequer surgiu como elemento analítico, em outros assumiu feições mais objetivas, alinhadas ao disposto por parte da literatura sobre o tema (Arns, 1985).

Para além de uma compreensão meramente normativa, isto é, de subsunção de certo fato à lei, alguns textos do Mecanismo Nacional propuseram reflexões quase sociológicas, apontando para relações de poder estabelecidas entre as pessoas no ambiente carcerário. No Complexo do Curado em Pernambuco, os peritos identificaram existir interações assimétricas entre as pessoas privadas de liberdade, por umas apresentarem maior poderio financeiro em detrimento de outras. Distante do proposto por regras de execução penal nacionais e internacionais que dispõem sobre a isonomia de tratamento aos custodiados, o Estado se omitiria de sua função de custódia a ponto de permitir que fossem travadas relações desiguais, gerando situações torturantes:

(...) é criada uma relação de submetimento entre os presos com e os sem recursos financeiros, desenvolvendo uma relação pautada pela desigualdade, cujo efeito é o empoderamento de um grupo de pessoas em detrimento do outro (...) (Brasil, 2016a, p. 29).

Essa interpretação se aproxima, em alguma medida, de uma leitura traçada pela Pastoral Carcerária (2018) e das discussões teóricas proferidas nas seções iniciais deste artigo, as quais indicam que a tortura constitui elemento estrutural da gestão prisional brasileira. Não resulta, pois, de más ações ou da perversão de determinados indivíduos, estando estreitamente 
vinculada ao processo massivo de encarceramento ${ }^{7}$, arquitetado para vitimar jovens, negros, pobres e habitantes de periferias urbanas do país. No entanto, esse tipo de análise contraria as recomendações de Nigel Rodley ao Brasil, baseadas na perspectiva sobre crimes de oportunidade, cujo teor é de que a tortura deve ser combatida através da redução de condições que oportunizam a sua perpetração. A nova interpretação se desloca da esfera de responsabilização individual, concentrando-se no processo de formulação e execução de políticas públicas. Sob esta ótica, a tortura apenas seria erradicada caso houvesse uma mudança de paradigma penal no país, no qual o encarceramento deixasse de ser o foco da segurança pública (Pastoral Carcerária, 2018).

Realizou-se uma discussão semelhante ao proposto pela Pastoral Carcerária no "Fórum Regional sobre o Protocolo Facultativo à Convenção da ONU Contra a Tortura na América Latina", realizado pela Associação de Prevenção à Tortura (APT), em 2014. Conforme um membro à época do Subcomitê de Prevenção à Tortura da ONU,

[a]s visitas regulares configuram, em si mesmas, um elemento da prevenção, se não anunciadas e realizadas de maneira sistemática. Contudo, de acordo com o Protocolo Facultativo, as visitas não possuem apenas esse propósito. Elas servem para gerar conhecimento específico sobre as condições que possibilitam a tortura e os maus tratos (APT, 2014, p. 46).

O encontro apontou para três perspectivas sobre a prevenção à tortura: o conceito de prevenção; o monitoramento preventivo e a atenção a casos individuais; e a prevenção para além das visitas [do MNPCT] (APT, 2014, p. 46-47). Portanto, aspectos preventivos requereriam uma perspectiva sistemática e ampla". A persistência da tortura não se baseia apenas nas

\footnotetext{
${ }^{7}$ Garland (2008) indica que a prisão se transformou, nas últimas décadas, no principal mecanismo de gerenciamento dos indivíduos criminosos sem qualquer pretensão socializadora. Com isso, a estratégia do super encarceramento vem sendo aprofundada, principalmente através da política contra as drogas. Por conseguinte, em junho de 2016, a população prisional brasileira ultrapassou, pela primeira vez, a marca de 700 mil pessoas privadas de liberdade, o que representa um aumento da ordem de $707 \%$ em relação ao total registrado no início da década de 1990 (DEPEN, 2017).
} 
situações majoritariamente encontradas nas visitas de Mecanismos Nacionais, mas sim no contexto de impunidade disseminada, nas políticas públicas problemáticas e na legislação deficiente.

O debate sobre omissão apresentado anteriormente torna-se central a este mote interpretativo. Mesmo que não as perpetrasse diretamente, o Estado estaria ciente das violações e de suas políticas transgressoras, mas nada faria. Entretanto, embora tenha havido certo esforço analítico nesse sentido, tal qual exposto no relatório de Pernambuco, o Mecanismo Nacional não se valeu dos dispositivos legais ou de outros tipos de discussões para se posicionar sobre a questão em seus diagnósticos. Quando falou em omissão, o órgão se manifestou genericamente, sem mencionar necessariamente a tortura e, portanto, sem implicar qualquer tipo de responsabilização. Nessa direção, no documento produzido a partir das visitas a prisões de Manaus, apontou-se para "a omissão do Estado em garantir a vida e outros direitos" (Brasil, 2016c, p. 28), nada mais sendo dito. Por certo, a questão não é muito aprofundada nas pesquisas nacionais, tampouco a literatura internacional reúne discussão robusta sobre o assunto.

Ao que parece, pelos distintos conceitos de tortura trabalhados nos relatórios em análise, a questão estaria em disputa. Ora fez-se mero esforço de subsumir práticas específicas à definição legal de tortura, ainda que não houvesse necessariamente um padrão para a normativa mobilizada; ora se indicou uma maior abrangência da questão, apontando-se, por exemplo, as relações de poder estabelecidas no ambiente de privação de liberdade; ora nem mesmo se tangenciou o debate. Não haveria consenso quanto ao tema. Possivelmente, os relatórios apenas espelham processos de discussão internos do órgão, os quais poderiam ser mais bem estudados em outros esforços de pesquisa, com foco nas dinâmicas de trabalho do Mecanismo Nacional.

Porém, haveria entendimentos mais firmes sobre o que é considerado "tortura" e sobre o que seriam "maus tratos"? A seção seguinte busca responder esta questão. 


\section{Nuances entre conceitos}

A definição jurídica de determinada violência como "tortura" ou como "maus tratos" envolve uma complexidade subjetiva e objetiva. Por um lado, abrange variados entendimentos sobre o fenômeno a ser nomeado juridicamente e, por outro, abarca o enquadramento jurídico, cujo efeito é gerar consequências em termos de responsabilização e punição. Há quem diga, inclusive, que o trabalho depende, em certa medida, da quantificação da dor e de sua intensidade (Pastoral Carcerária, 2018, p. 79), tangenciando uma tênue fronteira. Portanto, para se indicar se certo caso se referiu a uma prática ou a outra, exige-se uma descrição minuciosa e detalhada do ocorrido, da intenção dos agentes envolvidos e da caracterização do crime.

Já nos documentos formulados pelo Mecanismo Nacional, o termo "maus tratos" surgiu, com frequência, próximo a palavras e termos como "tortura", "tratamentos cruéis, desumanos e degradantes". A expressão costumou ser utilizada de forma genérica, sem um tratamento conceitual mais elaborado. Geralmente, foi exposta como forma de expor violências difusas, relacionadas às péssimas condições estruturais e à insalubridade das unidades de privação de liberdade:

(...) as pessoas se revezavam para sentar ou dormir, o que pode configurar maus tratos, senão tortura. (...) A temperatura elevada na cidade de Manaus, somada às condições descritas, conforma um cenário que propicia maus tratos e tratamentos degradantes às pessoas privadas de liberdade (Brasil, 2016c, p. 28).

Outra menção ao termo "maus tratos" se referiu à precariedade de atendimento e à assistência deficitária prestada às pessoas privadas de liberdade, configurando práticas propositais de restrição de alimentos, de itens higiênicos e de atendimento de saúde. De igual maneira, o isolamento prolongado e formas de imobilização das pessoas privadas de liberdade também foram mencionados como maus tratos nos relatórios do Mecanismo Nacional: 
(...) ausência de uma atenção à saúde orientada especificamente à mulher nas prisões pode se constituir como maus-tratos ou, quando não ofertada de maneira intencional ou mediante proibição do acesso à saúde, tais práticas podem ser consideradas como tortura (Brasil, 2018, p. 57).

Com esse nível de rotina as adolescentes podem passar até 23 horas por dia dentro dos alojamentos. O que se configura muito grave, uma nítida situação de maus tratos, a princípio, por negligência e omissão, não apenas da direção da unidade, mas do Distrito Federal (...) (Brasil, 2015b, p. 13).

Contudo, nem todos os documentos com descrições sobre cenários semelhantes aos citados nomearam tais situações como "maus tratos", sendo a perspectiva sobre a questão também fluida:

[a] água que consomem é a do chuveiro muitas vezes imprópria para consumo causando desconfortos estomacais, entre outros. Houve também relatos sobre a má qualidade da comida que por vezes a mesma chega até elas azeda ou imprópria para consumo (Brasil, 2015b, p. 23).

Em resumo, apesar de ser mobilizado para descrever situações de "falta", o termo "maus tratos" não foi usado com frequência nos relatórios do Mecanismo Nacional. No geral, apareceu em conjunto com a palavra "tortura", sendo utilizado apenas para descrever violências genéricas, tanto intencionais quanto não intencionais. Nesta interpretação, a prática teria, inclusive, mais proximidade ao funcionamento, à administração e à gestão das unidades de privação de liberdade. Estaria distante, pois, de atos de violência física e psíquica cometidos por funcionários contra as pessoas privadas de liberdade.

\section{Variações da tortura em distintos espaços de privação de liberdade}

A grande maioria das visitas do Mecanismo Nacional foi realizada em cárceres, seguida de centros socioeducativos e de estabelecimentos voltados 
a pessoas em sofrimento psíquico ${ }^{8}$. Portanto, embora haja um olhar mais acurado à questão carcerária, o órgão apresentou relativa heterogeneidade na execução de suas funções; explorou diferentes ambientes, o que, por sua vez, poderia gerar a incidência de distintos tipos de violações de direitos humanos. Isto é, cada tipo de estabelecimento explicitaria uma realidade de privação de liberdade específica que, portanto, sujeitaria as pessoas que lá estavam a práticas de tortura diferentes.

Entretanto, embora haja variações de espaços visitados, os relatos analisados pareceram relativamente homogêneos. Questões de cunho mais difuso tornaram-se ponto comum para todos os tipos de unidades de privação de liberdade que o órgão percorreu, podendo ser listados, entre outros aspectos: a) falta de acesso à saúde; b) precariedade da alimentação; c) ausência de acolhimento individual; e d) escassez de atividades de trabalho, educação e lazer:

[t]ampouco existe um diagnóstico realizado sobre a chegada da pessoa à instituição, bem como anotações sobre o Projeto Terapêutico Individual, como preconiza o Inciso III do Art. 22 da Lei 11.343/2006 e o Art. 7 da Resolução ANVISA 29/2011 (Brasil, 2015c, p. 8).

Além das rotinas obrigatórias escolares, as únicas opções que a unidade oferece de atividades são o projeto da "fazendinha", oficina de confecção de cartazes e aulas de informática, das quais participam um número restrito de adolescentes e por curto espaço de tempo. (...) para participar de tais atividades é preponderante o critério de comportamento disciplinar (Brasil, 2015a, p. 13).

Por outro lado, as violações foram detectadas de acordo com legislações temáticas específicas. Ao se olhar as unidades socioeducativas, mobilizaramse normas relativas ao acolhimento de crianças e adolescentes; ao se averiguar as condições carcerárias de um dado local, utilizaram-se leis penais,

${ }^{8}$ Entre 2015 e 2018, os peritos percorreram 28 prisões, quinze unidades para adolescentes em cumprimento de medida de internação, oito espaços de saúde mental e duas instituições de longa permanência para pessoas idosas. 
de execução penal e regras prisionais internacionais; ao se investigar as circunstâncias de privação de liberdade de uma comunidade terapêutica, foram usadas normativas da Anvisa e do Ministério da Saúde, como indicado no primeiro trecho acima. Em raros momentos foram utilizadas normativas mais genéricas de direitos humanos, como a Declaração Universal das Nações Unidas.

Portanto, em boa medida, o fato de o Mecanismo detectar um mesmo conjunto de violações em distintos espaços de privação de liberdade pode ser percebido como fruto de uma espécie de padronização em relação a garantias previstas em normativas nacionais e internacionais, sejam estas de direitos humanos ou não. Por outro lado, o órgão pareceu atribuir pesos distintos às transgressões às normas. Não à toa, o efeito de um adolescente em unidade de internação estar privado de participar de atividades educativas e de lazer foi analisado como mais grave em relação, por exemplo, a uma pessoa idosa estar sujeita à mesma condição em uma instituição de longa permanência. O primeiro caso poderia ser analisado como tortura pelo órgão e o segundo como maus tratos. As vulnerabilidades foram avaliadas como ímpares, ainda que estivesse em análise um mesmo tipo de violação, tendo em vista o espaço de privação de liberdade.

Em contrapartida, a violência física ganhou outra feição nos documentos, parecendo haver variações em sua perpetração de acordo com o tipo de ator vitimizado. As pessoas presas e os adolescentes autores de atos infracionais seriam alvos diretos da ação de órgãos de controle do Estado, como os compostos por agentes prisionais, agentes socioeducativos e policiais. Estes indivíduos privados de liberdade seriam os mais vulneráveis à força desmedidamente utilizada por agentes de segurança. Já a contenção física seria mais comum em instituições de saúde mental e em instituições de longa permanência para pessoas idosas. Por exemplo, os peritos relataram que, em sua visita ao hospital de custódia e tratamento psiquiátrico do Rio Grande do Sul, teriam se deparado com instrumentos policiais, como escudos, utilizados pela equipe de saúde local para reprimir situações de pessoas em surto: 
[c]om isso, ainda que os Protocolos de Enfermagem disponham sobre a excepcionalidade da contenção mecânica, na prática, abre-se margem para que esse procedimento seja realizado antes da execução da contenção química (Brasil, 2015e, p. 12).

Assim como as demais unidades visitadas no Complexo Penitenciário de Pedrinhas, a CADET também é marcada por uma intensa presença de agentes de segurança - sejam os próprios agentes penitenciários, terceirizados ou funcionários da SEJAP - armados e vestidos de forma ostensiva, com coletes, coturnos e balaclavas, nas cores preta e cinza (Brasil, 2015d, p. 20).

Tanto a violência física quanto outros tipos de violações mais difusas seriam uma constante em todos os espaços de privação de liberdade visitados pelo órgão. Entretanto, costumaram ser analisadas e, em alguma medida, mensuradas pelo Mecanismo Nacional conforme a vulnerabilidade de cada público averiguado.

\section{Reflexões para um novo debate sobre a tortura}

Toda a análise em torno dos relatórios do Mecanismo Nacional apontou para uma falta de padronização na conceituação da tortura. Quando as tipificações jurídicas ou outras abordagens foram mobilizadas pelo órgão, houve pouco aprofundamento e muitas flutuações interpretativas. Ao que parece, o conceito de "tortura" estaria em disputa e em construção, requerendo maior refinamento e reflexão. Provavelmente, os relatórios apenas espelhem processos internos do órgão, os quais poderiam ser mais bem compreendidos em outros estudos, cujo foco seria suas dinâmicas de trabalho.

No entanto, para além de uma crítica mais pontual em relação ao desenvolvido pelo órgão, cabe destacar que, talvez, essa dificuldade em homogeneizar um entendimento sobre a tortura decorra do tipo de abordagem que alicerçou a política brasileira sobre a pauta. Foi mencionado que o relator especial da ONU, Nigel Rodley, classificou o ato como "crime de oportunidade", sendo necessário, sob esta perspectiva, interferir nos 
fatores que propiciam a perpetração da violência. Nesse bojo, a dissuasão seria a estratégia central à prevenção do crime. A fim de se conhecer as violações, é preciso haver um mecanismo de visitas às unidades de privação de liberdade, cujo trabalho possibilite não apenas averiguar situações de tortura, mas indicar às autoridades que a possibilidade de monitoramento é ferramenta para inibi-las.

Em outras palavras, esta abordagem indica que o indivíduo opta por cometer ou não a tortura, partindo de critérios racionais para a tomada de decisão. E, nesse contexto, o Mecanismo Nacional seria um instrumento para demover essa pessoa de cometer a prática. A violência é reduzida, então, a uma mera ação, limitando-se seu entendimento a uma questão jurídica e desconsiderando-se aspectos estruturais e estruturantes relacionados. A Pastoral Carcerária vem se afastando desse tipo de perspectiva, conforme seus relatórios sobre a tortura em tempos de encarceramento em massa (2016; 2018). Projeta-se uma mudança de paradigma em torno do tema, baseado em uma pergunta fundamental: como pensar a tortura?

Sob essa linha analítica, a prática está em disputa, sendo mutável e historicamente construída. Não à toa, corresponde a questões difusas, manifestas em unidades de privação de liberdade na ausência de serviços básicos, na hiperlotação, na alimentação insuficiente, na insalubridade, nos regimes de isolamento, nos surtos de doenças, nas ameaças de violência, nas revistas vexatórias etc. Indo ao encontro do proposto pela literatura traçada neste artigo, a tortura se constitui, pois, em instrumento de gestão e manutenção da ordem, em um sistema mormente pautado por violações de todas as naturezas, cujo efeito seria reprimir classes socialmente e economicamente vulneráveis. De fato, alguns poucos relatórios do Mecanismo Nacional dialogaram com esse tipo de compreensão, mas sempre muito timidamente, sem qualquer aprofundamento. Pareceu ser mais uma iniciativa espontânea, isenta de qualquer consciência mais teórica e/ou política.

Conforme o prisma proposto pela Pastoral Carcerária, as políticas de enfrentamento à tortura em espaços de privação de liberdade já 
implementadas, baseadas em sistemas de monitoramento, seriam muito limitadas. Esses mecanismos seriam potentes para cercear uma ou outra situação típica do ambiente averiguado, mas se mostrariam incapazes de reprimir circunstâncias estruturais de violação. Ademais, a Pastoral Carcerária também tem indicado que a abordagem meramente jurídica em torno da tortura, baseada nas normativas nacionais e internacionais, é obsoleta. A mera subsunção de um fato à lei esvaziaria todo o conteúdo histórico e político que gira em torno do debate.

Portanto, a experiência de mecanismos de prevenção à tortura exige uma reflexão complexa sobre a noção de tortura, incluindo a perspectiva da prática como ferramenta de controle e dispositivo de gestão de populações submetidas a sistemas de privação de liberdade. Ainda que o artigo não tenha avançado muito nessa reflexão, espera-se que se tenha aberto um flanco para que esse empenho seja deflagrado em outros trabalhos.

Maria Gorete Marques de Jesus é Doutora em Sociologia, pesquisadora de pós-doutorado no Programa de Pós-Graduação em Sociologia da Universidade de São Paulo e pesquisadora do Núcleo de Estudos da Violência da Universidade de São Paulo.

$\triangle$ gorete.marques@gmail.com

Thais Lemos Duarte é Doutora em Ciências Sociais, pesquisadora de pós-doutorado no Programa de Pós-Graduação em Sociologia da Universidade Federal de Minas Gerais, pesquisadora do Centro de Estudos de Criminalidade e Segurança Pública.

$\triangle$ thais-duarte@hotmail.com 


\section{Referências}

1. ANGOTTI, Bruna; JESUS, José; JESUS, Maria G. M. de. Enfrentando la tortura en Brasil: balance de los desafíos de la política de prevención y combate a la tortura. In: SCHUTTENBERG, Mauricio et al. Gestión de la inseguridad, violencias y sistema penal. Temperley: Tren en Movimiento, 2018. p. 359-379.

2. ARNS, Paulo E. Brasil nunca mais. 41. ed. São Paulo: Vozes, 1985.

3. ASSOCIAÇÃO PARA A PREVENÇÃO DA TORTURA (APT). Prevenir a tortura

- uma responsabilidade compartilhada. Fórum Regional sobre o Protocolo Facultativo à Convenção da ONU contra a Tortura na América Latina. Cidade do Panamá: Associação para a Prevenção da Tortura, 2014.

4. BEATO, Cláudio, Fo; PEIXOTO, Betânia T.; ANDRADE, Mônica V. Crime, oportunidade e vitimização. Revista Brasileira de Ciências Sociais, v. 19, n. 55, p. 73-89, 2004. http://dx.doi.org/10.1590/S0102-69092004000200005

5. BECCARIA, Cesare. Dos delitos e das penas. São Paulo: Gaetano Dibenedetto, 1996.

6. BOZZA, Fábio da S. Teorias da pena: do discurso jurídico à crítica criminológica. Rio de Janeiro: Lumen Juris, 2013.

7. BRASIL. Mecanismo Nacional de Prevenção e Combate à Tortura (MNPCT). Relatório Anual 2017-2018. Brasília: MNPCT, 2018.

8. BRASIL. Mecanismo Nacional de Prevenção e Combate à Tortura (MNPCT). Relatório Anual 2015-2016. Brasília: MNPCT, 2016 a.

9. BRASIL. Mecanismo Nacional de Prevenção e Combate à Tortura (MNPCT). Relatório de Visitas a Pernambuco. Brasília: MNPCT, julho de $2016 \mathrm{~b}$.

10. BRASIL. Mecanismo Nacional de Prevenção e Combate à Tortura (MNPCT). Relatório de visitas a unidades prisionais de Manaus. Brasília, janeiro de 2016c.

11. BRASIL. Mecanismo Nacional de Prevenção e Combate à Tortura (MNPCT). Relatório de Visitas ao Sistema de Atendimento Socioeducativo ao Adolescente do Ceará. Brasília: MNPCT, janeiro de 2016d.

12. BRASIL. Mecanismo Nacional de Prevenção e Combate à Tortura (MNPCT). Relatório de visitas à Unidade de Internação de Planaltina. Brasília: MNPCT, julho de 2015a.

13. BRASIL. Mecanismo Nacional de Prevenção e Combate à Tortura (MNPCT). Relatório de visitas à Unidade de Internação de Santa Maria. Brasília: MNPCT, novembro de $2015 \mathrm{~b}$.

14. BRASIL. Mecanismo Nacional de Prevenção e Combate à Tortura (MNPCT). Relatório de visitas ao Centro de Recuperação Leão de Judá do Distrito Federal. Brasília: MNPCT, julho de 2015c. 
15. BRASIL. Mecanismo Nacional de Prevenção e Combate à Tortura (MNPCT). Relatório de visitas ao Complexo de Pedrinhas Maranhão. Brasília: MNPCT, novembro de $2015 \mathrm{~d}$.

16. BRASIL. Mecanismo Nacional de Prevenção e Combate à Tortura (MNPCT). Relatório de Visitas ao Instituto Psiquiátrico Forense do Rio Grande do Sul. Brasília: MNPCT, novembro de 2015e.

17. BRASIL. Mecanismo Nacional de Prevenção e Combate à Tortura (MNPCT). Relatório de visitas ao Presídio Militar Romão Gomes do Estado de São Paulo. Brasília: MNPCT, outubro de $2015 f$.

18. BRASIL. Presidência da República. Decreto no 8.154, de 16 de dezembro de 2013a. Regulamenta o funcionamento do Sistema Nacional de Prevenção e Combate à Tortura, a composição e o funcionamento do Comitê Nacional de Prevenção e Combate à Tortura e dispõe sobre o Mecanismo Nacional de Prevenção e Combate à Tortura. Diário Oficial da União, 17 dez. $2013 a$.

19. BRASIL. Presidência da República. Lei n 12.847, de 02 de agosto de 2013. Institui o Sistema Nacional de Prevenção e Combate à Tortura; cria o Comitê Nacional de Prevenção e Combate à Tortura e o Mecanismo Nacional de Prevenção e Combate à Tortura; e dá outras providências. Diário Oficial da União, 5 ago. 2013 b.

20. BRASIL. Presidência da República. Decreto no 6.085 de 19 de abril de 2007. Promulga o Protocolo Facultativo à Convenção contra a Tortura e Outros Tratamentos ou Penas Cruéis, Desumanos ou Degradantes, adotado em 18 de dezembro de 2002. Diário Oficial da União, 20 abr. 2007.

21. BRASIL. Presidência da República. Plano de ações integradas para prevenção e controle da tortura no Brasil. Brasília, dezembro de 2005. Disponível em: https://bibliotecadigital.mdh.gov.br/jspui/bitstream/192/1141/1/_plano_br_ acoes_integradas_prevencao_tortura.pdf

22. BRASIL, Superior Tribunal de Justiça. Protocolo de ação contra a tortura. Tribuna [online]. 29 de junho de 2003. Disponível em: https://www.tribunapr. com.br/noticias/protocolo-de-acao-contra-a-tortura/

23. BRASIL. Presidência da República. Lei no 9.455, de 7 de abril de 1997. Define os crimes de tortura e dá outras providências. Diário Oficial da União, 8 abr. 1997.

24. BRASIL. Presidência da República. Decreto no 98.386, de 9 de novembro de 1989. Promulga a Convenção Interamericana para Prevenir e Punir a Tortura. Diário Oficial da União, 13 nov. 1989.

25. CALDERONI, Vivian; JESUS, Maria G. M. de. Julgando a tortura: análise de jurisprudência nos tribunais de justiça do Brasil (2005-2010). São Paulo: ACATBrasil/Conectas/NEV-USP/IBCCRIM/ Pastoral Carcerária, 2015. 
26. CARDIA, Nancy; ASTOLFI, Roberta (orgs.). Tortura na era dos direitos humanos. São Paulo: Edusp, 2014.

27. COHEN, Lawrence E.; KLUEGEL, James R.; LAND, Kenneth C. Social inequality and predatory criminal victimization: an exposition and test of a formal theory. American Sociological Review, v. 46, n. 5, p. 505-524, 1981.

28. COMPARATO, Fábio K. Rumo à Justiça. São Paulo: Saraiva, 2010.

29. CONDEGE - Colégio Nacional dos Defensores Públicos Gerais. Condege emite nota sobre o Decreto no 9.831/2019, que altera o funcionamento e composição do Mecanismo Nacional de Prevenção e Combate à Tortura. Condege [site]15 de junho de 2019. Disponível em: <http://www.condege.org. br/publicacoes/noticias/condege-emite-nota-sobre-decreto-n-9-831-2019-quealtera-o-funcionamento-e-composicao-do-mecanismo-nacional-de-prevencaoe-combate-a-tortura $>$

30. DAUFEMBACK, Valdirene; LIMA, Susan F. C. de; MELO, Felipe A. L. de; SANTOS, Thandara; DUARTE, Thais L.; GIVISIEZ, Fernanda M. Nota técnica, de 18 de janeiro de 2018: análise sobre os impactos da alteração da resolução 09, de 18 de novembro de 2011, do CNPCP que define as diretrizes para arquitetura penal no Brasil. Brasília: Secretaria de Direitos Humanos da Presidência da República, 2018.

31. DEPARTAMENTO PENITENCIÁRIO NACIONAL (DEPEN). Levantamento Nacional de informações penitenciárias. INFOPEN, junho de 2016. Brasília: Ministério da Justiça, 2017.

32. ELIAS, Norbert. O processo civilizador. v. 2, Formação do Estado e civilização. Rio de Janeiro: Jorge Zahar, 1993.

33. FOUCAULT, Michel. Vigiar e punir: história de violência das prisões. 35. ed. Petrópolis: Vozes, 2008.

34. FRANCO, Ana P. N. Distinção entre maus-tratos e o art. 1ํ, II, da Lei de tortura. Boletim IBCCRIM, n. 62, p. 11, jan. 1998.

35. GARLAND, David. A cultura do controle: crime e ordem social na sociedade contemporânea. Rio de Janeiro: Revan, 2008.

36. GODOI, Rafael. Para uma reflexão sobre os efeitos sociais do encarceramento. Revista Brasileira de Segurança Pública, v. 5, n. 8, p. 138-154, 2011.

37. GOFFMAN, Erving. Manicômios, prisões e conventos. São Paulo: Perspectiva, 2007.

38. GOMES, Mayara de S. Isso é tortura? Disputas, consensos e narrativas na construção do crime de tortura na cidade de São Paulo. 2017. Dissertação (Mestrado em Ciências Sociais) - Programa de Pós-Graduação em Ciências Humanas, Universidade Federal do ABC, São Bernardo do Campo, 2017. 
39. JESUS, Maria G. M. de. O crime de tortura - uma análise dos processos criminais na cidade de São Paulo. São Paulo: IBCCRIM, 2010.

40. MAIA, Luciano M. Do controle judicial da tortura institucional: à luz do direito internacional dos direitos humanos, 2006. Tese (Doutorado em Direito) - Curso de Pós-Graduação em Direito, Universidade Federal de Pernambuco, Recife, 2006.

41. MOVIMENTO NACIONAL DE DIREITOS HUMANOS (MNDH). Relatório final da Campanha Nacional Permanente de Combate à Tortura e à Impunidade. Brasília: MNDH/ SEDH? 2003a. http://www.dhnet.org.br/denunciar/tortura/ campanha/relatorio_final_mndh_campanha_tortura.pdf

42. PASTORAL CARCERÁRIA. Tortura em tempos de encarceramento em massa. São Paulo: Pastoral Carcerária/CNBB, 2016.

43. PASTORAL CARCERÁRIA. Tortura em tempos de encarceramento em massa II. São Paulo: Pastoral Carcerária - CNBB, 2018.

44. RODLEY, Nigel. Report of the Special Rapporteur, Sir Nigel Rodley, submitted pursuant to Commission on Human Rights resolution 2000/43. Addendum. Visit to Brazil. E/CN.4/2001/66/Add.2. Genebra: UN Economic and Social Council, 30 March 2001. Disponível em: https://digitallibrary.un.org/record/437371 ?ln=en.

45. ROXIN, Claus. Estudos de direito penal. 2. ed. Rio de Janeiro: Renovar, 2008.

46. SALLA, Fernando; JESUS, José; JESUS, Maria G. M. Investigação e processamento de crimes de tortura em Goiânia, Curitiba e Belo Horizonte. In: PARESCHI, Ana C. C.; ENGEL, Cíntia L.; BAPTISTA, Gustavo C. (orgs.). Direitos humanos, grupos vulneráveis e segurança pública. 1. ed. Brasília: SENASP, Ministério da Justiça, 2016, v. 6, p. 111-148.

47. WEBER. Max. A ética protestante e o espírito do capitalismo. São Paulo: Companhia das Letras, 2004.

Recebido em: 21 ago. 2019.

Aceito em: 09 jan. 2020. 
